OPEN ACCESS

Edited by: Nicole Thielens, UMR5075 Institut de Biologie Structurale (IBS), France

Reviewed by: Kevan Hartshorn, Boston University, United States Howard William Clark, University of Southampton, United Kingdom

*Correspondence: Jiu-Yao Wang a122@mail.ncku.edu.tw Uday Kishore uday.kishore@brunel.ac.uk; ukishore@hotmail.com

Specialty section:

This article was submitted to Molecular Innate Immunity, a section of the journal

Frontiers in Immunology

Received: 14 December 2020 Accepted: 20 April 2021 Published: 14 May 2021

Citation:

Hsieh M-H, Beirag N, Murugaiah V

Chou Y-C, Kuo W-S, Kao H-F, Madan T, Kishore $U$ and Wang $J-Y$ (2021) Human Surfactant Protein D Binds Spike Protein and Acts as an

Entry Inhibitor of SARS-COV-2 Pseudotyped Viral Particles.

Front. Immunol. 12:641360. doi: 10.3389/fimmu.2021.641360

\section{Human Surfactant Protein D Binds Spike Protein and Acts as an Entry Inhibitor of SARS-CoV-2 Pseudotyped Viral Particles}

\author{
Miao-Hsi Hsieh ${ }^{1,2,3}$, Nazar Beirag ${ }^{4}$, Valarmathy Murugaiah ${ }^{4}$, Yu-Chi Chou ${ }^{5}$, \\ Wen-Shuo Kuo ${ }^{2}$, Hui-Fang $\mathrm{Kao}^{2,6}$, Taruna Madan ${ }^{7}$, Uday Kishore ${ }^{4 *}$ \\ and Jiu-Yao Wang ${ }^{2,3,8 *}$ \\ ${ }^{1}$ Institute of Basic Medical Sciences, College of Medicine, National Cheng Kung University, Tainan, Taiwan, ${ }^{2}$ Center for \\ Allergy \& Clinical Immunology Research (ACIR), National Cheng Kung University Hospital, College of Medicine, National \\ Cheng Kung University, Tainan, Taiwan, ${ }^{3}$ Department of Pediatrics, College of Medicine, National Cheng Kung University \\ Hospital, Tainan, Taiwan, ${ }^{4}$ Biosciences, College of Health, Medicine and Life Sciences, Brunel University London, \\ Uxbridge, United Kingdom, ${ }^{5}$ Biomedical Translation Research Center (BioTReC), Academia Sinica, Taipei, Taiwan, \\ ${ }^{6}$ Department of Nursing, National Tainan Junior College of Nursing, Tainan, Taiwan, ${ }^{7}$ Department of Innate Immunity, \\ ICMR-National Institute for Research in Reproductive Health, Mumbai, India, ${ }^{8}$ Children's Hospital, China Medical \\ University, Taichung, Taiwan
}

Human SP-D is a potent innate immune molecule whose presence at pulmonary mucosal surfaces allows its role in immune surveillance against pathogens. Higher levels of serum SP-D have been reported in the patients with severe acute respiratory syndrome coronavirus (SARS-CoV). Studies have suggested the ability of human SP-D to recognise spike glycoprotein of SARS-CoV; its interaction with HCoV-229E strain leads to viral inhibition in human bronchial epithelial (16HBE) cells. Previous studies have reported that a recombinant fragment of human SP-D (rfhSP-D) composed of 8 Gly-X-Y repeats, neck and $\mathrm{CRD}$ region, can act against a range of viral pathogens including influenza $A$ Virus and Respiratory Syncytial Virus in vitro, in vivo and ex vivo. In this context, this study was aimed at examining the likely protective role of ifhSP-D against SARS-CoV-2 infection. rfhSP-D showed a dose-responsive binding to S1 spike protein of SARS-CoV-2 and its receptor binding domain. Importantly, rfhSP-D inhibited interaction of S1 protein with the HEK293T cells overexpressing human angiotensin converting enzyme 2 (hACE2). The protective role of rfhSP-D against SARS-CoV-2 infection as an entry inhibitor was further validated by the use of pseudotyped lentiviral particles expressing SARS-CoV-2 S1 protein; 0.5 RLU fold reduction in viral entry was seen following treatment with rfhSP-D $(10 \mu \mathrm{g} / \mathrm{ml})$. These results highlight the therapeutic potential of rfhSP-D in SARS-CoV-2 infection and merit pre-clinical studies in animal models.

Keywords: innate immunity, SARS-COV-2, spike protein, human pulmonary collectins, surfactant protein D, angiotensin converting enzyme 2 


\section{INTRODUCTION}

Human surfactant protein D (SP-D), a collagen-containing C-type lectin and a member of the collectin family, is known to be involved in pulmonary surfactant homeostasis and immunity (1). SP-D is primarily synthesized and secreted into the air space of the lungs by alveolar type II and Clara cells $(2,3)$. Its primary structure is organized into four regions: a cysteinerich $\mathrm{N}$-terminus, a triple-helical collagen region composed of Gly-X-Y triplets repeats, an $\alpha$-helical coiled neck region, and a C-terminal C-type lectin or carbohydrate recognition domain (CRD) (1). As a versatile innate immune molecule, SP-D can interact with a number of pathogens, triggering clearance mechanisms against viruses, bacteria, and fungi, as well as and apoptotic cells (4).

Direct interaction of SP-D with a range of viruses results in viral neutralization, and induction of phagocytosis in vitro $(5,6)$. Anti-viral activity of human SP-D against Influenza A Virus (IAV) infection has been reported. SP-D binds haemagglutinin (HA) and neuraminidase (NA) glycoproteins of IAV, and inhibits hemagglutination at initial stages of the infection (7). A recombinant fragment of human SP-D (rfhSP-D), composed of homotrimeric neck and CRD region, was also shown to bind HA, NA and Matrix 1 (M1) protein of IAV, and act as an entry inhibitor of IAV infection on A549 lung epithelial cells (8). Furthermore, SP-D binds to gp120 and inhibits HIV-1 infectivity and replication (9) in U937 monocytic cells, Jurkat $\mathrm{T}$ cells and PBMCs, in addition to suppressing HIV-1 triggered cytokine storm (10). Higher levels of serum SP-D have been detected in patients infected with severe acute respiratory syndrome (SARS) coronavirus (SARS-CoV) (11). SARS-CoV spike glycoprotein is recognized by SP-D (12). Interaction between SP-D and HCoV-229E, another coronavirus strain, leads to inhibition of viral infection in human bronchial epithelial (16HBE) cells (13).

SARS coronavirus 2 (SARS-CoV-2) is an enveloped $\beta$ coronavirus, belonging to the Coronaviridae family of viruses, and is genetically close to SARS-CoV ( $\sim 80 \%$ sequence similarity) and bat coronavirus RaTG13 $(96.2 \%)(14,15)$. The envelope of SARS-CoV-2 is coated by the spike (S) glycoprotein, a small envelope (E) glycoprotein, membrane (M) glycoprotein, nucleocapsid $(\mathrm{N})$ protein, and several putative accessory proteins (15-17). The SARS-CoV-2 mediates its entry into the host cell using the $S 1$ sub-unit of the $S$ glycoprotein by binding to angiotensin-converting enzyme 2 (ACE2) receptor (18). However, viral entry into the host cells requires not only binding to the ACE2 receptor, but also priming of the $\mathrm{S}$ protein by a transmembrane protease serine 2 (TMPRSS2) via cleavage of the S protein at S1/S2 sites (19). This cleavage is very crucial for the virus-host cell membrane fusion and cell entry (20). Following viral replication, assembly, and release, the infected host cells undergo pyroptosis, thus, releasing DamageAssociated Molecular Patterns (DAMPs) (21). DAMPs are then recognised by surrounding macrophages and monocytes that respond to viral infection by inducing cytokine storm (22). However, in some cases, an impaired or dysregulated immune response can also occur, causing an Acute Respiratory Distress Syndrome (ARDS) $(23,24)$.

Designing and developing new anti-viral therapeutic strategies are crucial for treating SARS-CoV-2. The likely antiviral effects of immune-surveillance molecules like SP-D have not been well investigated in SARS-CoV-2 infection. Since rfhSP-D has been shown to inhibit viral infection and replication of IAV and HIV-1, this study was aimed at investigating whether rfhSP-D can interfere with the binding of SARS-CoV-2 S1, and receptor binding domain (RBD) of SARS-CoV-2 with ACE-2. The ability of rfhSP-D to inhibit infection of SARS-CoV-2 was examined using pseudotyped lentiviral particles expressing SARS-CoV-2 S1 protein.

\section{MATERIAL AND METHODS}

\section{Expression and Purification of rfhSP-D}

DNA sequences coding for $8 \mathrm{Gly}-\mathrm{X}-\mathrm{Y}$ repeats of collagen region, $\alpha$-helical neck and CRD region of human SP-D were cloned under T7 promoter and expressed in Escherichia coli BL21 $(\lambda D E 3)$ pLysS using construct pUK-D1 $(25,26)$. Primary bacterial inoculum $(25 \mathrm{ml})$ was grown in Luria-Bertani (LB) medium (500 ml) with $34 \mu \mathrm{g} / \mathrm{ml}$ chloramphenicol and $100 \mu \mathrm{g} / \mathrm{ml}$ ampicillin (Sigma-Aldrich) at $37^{\circ} \mathrm{C}$ until an $\mathrm{OD}_{600}$ of 0.6 was reached. Following isopropyl $\beta$-D-thiogalactoside (IPTG) $(0.5 \mathrm{mM})$ induction, the transformed $E$. coli cells were grown further for another $3 \mathrm{~h}$ at $37^{\circ} \mathrm{C}$ on a shaker. The bacterial cells were harvested by centrifugation $\left(5000 \mathrm{rpm}, 4^{\circ} \mathrm{C}, 10 \mathrm{~min}\right.$ ), and the cell pellet was re-suspended in lysis buffer containing $50 \mathrm{mM}$ Tris-HCl, pH 7.5, $200 \mathrm{mM} \mathrm{NaCl}, 5 \mathrm{mM}$ EDTA, 0.1\% v/v Triton $\mathrm{X}-100,0.1 \mathrm{mM}$ phenylmethane sulfonyl fluoride (PMSF) (SigmaAldrich), and $50 \mu \mathrm{g}$ lysozyme/ml (Sigma-Aldrich) at $4^{\circ} \mathrm{C}$ for $1 \mathrm{~h}$. The lysed cell lysate was then sonicated at $60 \mathrm{~Hz}$ for $30 \mathrm{sec}$ with an interval of 2 min (12 cycles) using a Soniprep 150 (MSE, London, UK), followed by centrifugation (12,000 rpm, $15 \mathrm{~min}$ ). The inclusion bodies were denatured using buffer $(50 \mathrm{ml})$ containing $0.5 \mathrm{M}$ Tris- $\mathrm{HCl}, 0.1 \mathrm{M} \mathrm{NaCl}, \mathrm{pH} 7.5$ and $8 \mathrm{M}$ urea for $1 \mathrm{~h}$ at $4^{\circ} \mathrm{C}$. The soluble fraction was dialysed against the same buffer containing varied concentration of urea $(4 \mathrm{M}, 2 \mathrm{M}, 1 \mathrm{M}, 0$ $\mathrm{M})$ for $2 \mathrm{~h}$ each. The refolded material was then dialysed against affinity buffer (50 mM Tris-HCl, pH7.5, $100 \mathrm{mM} \mathrm{NaCl}, 10 \mathrm{mM}$ $\mathrm{CaCl}_{2}$ ) for $2 \mathrm{~h}$ at $4^{\circ} \mathrm{C}$. The affinity buffer dialysed supernatant was then loaded on to a maltose-agarose column $(5 \mathrm{ml})$ (SigmaAldrich); the bound rfhSP-D was eluted using elution buffer containing $50 \mathrm{mM}$ Tris- $\mathrm{HCl}, 100 \mathrm{mM} \mathrm{NaCl}$, and $10 \mathrm{mM}$ EDTA. Purified rfhSP-D was run on SDS-PAGE to assess its purity. LPS was removed using Endotoxin Removal Resin (Sigma-Aldrich). LPS level was determined using QCL-1000 Limulus amebocyte lysate system (Lonza) and found to be $<5 \mathrm{pg} / \mu \mathrm{g}$ of rfhSP-D.

\section{ELISA}

Polystyrene microtiter plates (Sigma-Aldrich) were coated with SARS-CoV-2 spike S1 protein (NativeAntigen S1. NCBI accession number YP_009724390.1 AA1-674, produced in HEK 293 cells; Acro, AA Val 16 - Arg 685, accession \# 
QHD43416.1, produced in HEK 293 cells) or RBD (Acro, Arg319-Phe541, accession \#QHD43416.1, produced in HEK 293 cells) (27) $(5 \mu \mathrm{g} / \mathrm{ml}, 100 \mu \mathrm{l} /$ well $)$ at $4^{\circ} \mathrm{C}$ overnight using carbonate/bicarbonate (CBC) buffer, pH 9.6 (Sigma-Aldrich). The following day, the microtiter wells were washed three times with Tris Buffered Saline-Tween (TBST, pH 7.2-7.4) containing $0.05 \% \mathrm{v} / \mathrm{v}$ Tween 20 (Sigma-Aldrich) and $5 \mathrm{mM} \mathrm{CaCl}_{2}$ (Thermo Fisher Scientific). The wells were then blocked by TBS containing $1 \% \mathrm{w} / \mathrm{v}$ BSA and $5 \mathrm{mM} \mathrm{CaCl}_{2}$, for $1 \mathrm{~h}$. After washing three times with TBST, the wells were incubated with two-fold dilutions of rfhSP-D or recombinant human full-length SP-D (hFL-SP-D, R\&D, 1920-SP, produced in HEK 293 cells) protein (100 $\mu \mathrm{l} /$ well) in the blocking buffer at $4^{\circ} \mathrm{C}$ overnight. Next day, the wells were washed and then incubated with biotinylated mouse anti-Human SP-D detection antibody (1:180) (R\&D Systems) for $2 \mathrm{~h}$ at room temperature. After washing, the wells were incubated with Streptavidin horseradish peroxidase (HRP)-conjugate (1:40; R\&D System) for $20 \mathrm{~min}$, followed by washing three times. TMB substrate ( $100 \mu \mathrm{l} /$ well; Thermo Fisher Scientific) was added to each well and the reaction was stopped using $1 \mathrm{M} \mathrm{H}_{2} \mathrm{SO}_{4}$ (50 $\mu \mathrm{l} /$ well; Sigma-Aldrich). Absorbance at 450nm were measured by VersaMax ${ }^{\text {TM }}$ ELISA Microplate Reader.

\section{Competition ELISA}

Polystyrene microtiter plates were coated with $2 \mu \mathrm{g} / \mathrm{ml} \mathrm{rfhSP-D}$ (100 $\mu \mathrm{l} /$ well) at $4^{\circ} \mathrm{C}$ overnight using $\mathrm{CBC}$ buffer and washed three times with TBS buffer containing $0.05 \%$ v/v Tween 20 and $5 \mathrm{mM} \mathrm{CaCl} 2$. The wells were blocked with TBS containing $1 \%$ BSA and $5 \mathrm{mM} \mathrm{CaCl}_{2}$ for $1 \mathrm{~h}$. The wells were then washed three times and incubated with SARS-CoV-2 spike S1 protein (sheepIgG tag) or RBD (His-tag) (2.5 or $5 \mu \mathrm{g} / \mathrm{ml}, 100 \mu \mathrm{l} /$ well) separately in blocking buffer containing $10 \mathrm{mM}$ maltose and $10 \mathrm{mM}$ EDTA at $4^{\circ} \mathrm{C}$ overnight. Next day, the wells were washed and then incubated with anti-sheep IgG-HRP antibodies (Genetex, GTX27111, $0.5 \mu \mathrm{g} / \mathrm{ml}, 100 \mu \mathrm{l} /$ well) $(1: 2000)$ or anti-His antibodies (Genetex, GTX628914, $0.5 \mu \mathrm{g} / \mathrm{ml}, 100 \mu \mathrm{l} /$ well) (1:2000) for $2 \mathrm{~h}$. For the detection of RBD binding, the wells were further incubated with anti-mouse IgG antibody (Abcam, ab6728, $0.5 \mu \mathrm{g} / \mathrm{ml}, 100 \mu \mathrm{l} /$ well $)$ (1:2000) for $2 \mathrm{~h}$. After washing, the plates were incubated with TMB substrate $(100 \mu \mathrm{l} /$ well $)$ and then quenched with $1 \mathrm{M} \mathrm{H}_{2} \mathrm{SO}_{4}(50 \mu \mathrm{l} /$ well $)$. Absorbance at $450 \mathrm{~nm}$ was recorded by VersaMax ${ }^{\mathrm{TM}}$ ELISA Microplate Reader.

\section{Western Blotting}

HEK293T and HEK293T-ACE2 cells $\left(0.5 \times 10^{5}\right)$ were lysed by RIPA buffer (Thermo Fisher Scientific) containing protease inhibitor (AMRESCO VWR life sciences) on ice for 15 minutes and then centrifugation (13000 rpm, $\left.4^{\circ} \mathrm{C}, 15 \mathrm{~min}\right) .30 \mu \mathrm{g}$ samples resuspended in Laemmli sample buffer $(10 \mu \mathrm{l})$ and heated at $100^{\circ} \mathrm{C}$ for 10 minutes. The samples were loaded into an SDS-PAGE $(8 \%$ $\mathrm{v} / \mathrm{v})$ gel and then electrophoretically transferred onto the PVDF membrane $(320 \mathrm{~mA}$ for $2 \mathrm{~h}$ ) (Sigma-Aldrich) in transfer buffer [25mM Tris-HCl pH 7.5, $190 \mathrm{mM}$ glycine (Sigma-Aldrich), and $20 \% \mathrm{v} / \mathrm{v}$ methanol (Thermo Fisher Scientific)]. The membranes were blocked by $5 \% \mathrm{w} / \mathrm{v}$ dried milk powder (Sigma-Aldrich) diluted in TBS+ $0.05 \% \mathrm{v} / \mathrm{v}$ Tween 20 (TBST) for $1 \mathrm{~h}$ at room temperature and incubated with anti-SARS-CoV-2 (COVID-19)
Spike antibody (GeneTex, GTX135356; 1:1000) or anti-ACE2 antibody [SN0754] (GeneTex, GTX01160; 1:1000) at $4^{\circ} \mathrm{C}$ overnight. The membranes were washed three times and probed with secondary Goat anti-rabbit IgG horseradish peroxidase (HRP)-conjugate (1:10000; Fisher Scientific) for $1 \mathrm{~h}$ at room temperature. Following TBST washes, the protein expression was measured by Western Lightning Plus ECL (PerkinElmer) and chemiluminescent detection was performed using FluorChem R system (ProteinSimple, San Jose, CA, USA).

\section{Cell Culture and Treatments}

Human embryonic kidney (HEK) 293T or HEK293T cells overexpressing ACE2 receptor (HEK293T-ACE2) were cultured in complete Gibco Dulbecco's Modified Eagle Medium (DMEM), supplemented with $10 \% \mathrm{v} / \mathrm{v}$ fetal bovine serum (FBS), $100 \mathrm{U} / \mathrm{ml}$ penicillin (Sigma-Aldrich) and $100 \mu \mathrm{g} / \mathrm{ml}$ streptomycin (SigmaAldrich), and left to grow at $37^{\circ} \mathrm{C}$ in the presence of $5 \% \mathrm{v} / \mathrm{v} \mathrm{CO}_{2}$ for approximately $48 \mathrm{~h}$ before passaging. ACE2-stably expressing HEK-293T cells were selected by Blasticidin S HCl (Thermo Fisher Scientific). Since HEK293T cells were adherent, they were detached using $2 \times$ Trypsin-EDTA (0.5\%) (Thermo Fisher Scientific) for $10 \mathrm{~min}$ at $37^{\circ} \mathrm{C}$. Cells were then centrifuged at $1,500 \mathrm{rpm}$ for $5 \mathrm{~min}$, followed by re-suspension in complete DMEM medium. To determine the cell count and viability, an equal volume of the cell suspension and Trypan Blue $(0.4 \% \mathrm{w} / \mathrm{v})$ (Thermo Fisher Scientific) solution were vortexed, followed by cell count using a hemocytometer with Neubauer rulings (Sigma-Aldrich). Cells were then re-suspended in complete DMEM for further use.

\section{Generation of ACE2-Stably Expressing HEK-293T Cells}

Human ACE2 gene was amplified from MGC library (cDNA clone MGC:47598) by using Kapa HiFi PCR kit (Kapa Biosystems), and sub-cloned into NheI and EcoRI sites of pLAS2w.Pbsd (a lentiviral transfer vector from RNA core, Academia Sinica, Taiwan) by using GenBuilderTM Cloning kit (GeneScript $\left.{ }^{\circledR}\right)$. For generation of VSVG pseudotyped lentivirus carrying human ACE2 gene, three plasmids (pCMV-DR8.91, pLAS2w.ACE2.Pbsd and pMD.G) were transiently transfected into HEK-293T cells by using TransIT@-LT1 transfection reagent (Mirus). The culture medium was harvested to infect HEK-293T cells, and then the infected cells were selected with $5 \mu \mathrm{g} / \mathrm{ml}$ blasticidin for one week to generate HEK-293T-ACE2 stable cells.

\section{Flow Cytometry}

ACE2 expression was assessed between HEK293T cells overexpressing ACE2 receptor (HEK293T-ACE2) and HEK293T cells alone using flow cytometry. Briefly, both ACE2-transfected and non-transfected HEK293T cells $\left(1 \times 10^{5}\right.$ cells) were incubated with ACE2 antibody [N1N2, N-term (GeneTex, GTX101395), (1:250)] for $1 \mathrm{~h}$ at room temperature. Following PBS washes, the cells were probed with Goat antiRabbit IgG (H+L) Cross-Adsorbed Secondary Antibody linked to Alexa Fluor 647 (Thermo Fisher Scientific) $(0.6 \mu \mathrm{l} / 100 \mu \mathrm{l}$ per tube) for $1 \mathrm{~h}$ at room temperature in dark. After washing with PBS, the cells were resuspended in FACS buffer (PBS containing $2 \%$ FBS) and subjected to flow cytometry. 
For binding experiment using rfhSP-D (27), SARS-CoV-2 S1 protein containing a C-terminal His-tag (Acro; S1N-C52H3) $(5 \mu \mathrm{g} / \mathrm{ml})$ was tagged with anti-His antibody (Genetex; GT359) $(1: 100)$ at $4^{\circ} \mathrm{C}$ for $1 \mathrm{~h}$, followed by pre-incubation with a series of two-fold dilutions of rfhSP-D $(10 \mu \mathrm{g} / \mathrm{ml})$ or mock (medium only) at $4^{\circ} \mathrm{C}$ for $1 \mathrm{~h}$. HEK293T-ACE2 cells ( $1 \times 10^{5}$ cells) were incubated in DMEM incomplete medium with the mixture of SARS-CoV-2 S1 protein, anti-His antibodies and rfhSP-D at $37^{\circ} \mathrm{C}$ for $2 \mathrm{~h}$. The cells were collected and washed with FACS buffer twice and incubated with anti-mouse IgG-PE conjugate (Genetex, GTX25881) (1:100) for $30 \mathrm{~min}$ and washed three times. The live cells were gated from FSC vs. SSC dot plot in order to determine the PE positive cells containing S1 on their surface by CytoFLEX.

\section{Fluorescence Microscopy}

HEK293T and HEK293T-ACE2 cells $\left(0.5 \times 10^{5}\right)$ were grown on coverslips in complete DMEM medium overnight under standard culture conditions, as mentioned above. Next day, cells were washed with PBS three times, the coverslips were fixed with $4 \% \mathrm{v} / \mathrm{v}$ paraformaldehyde (Sigma-Aldrich) for 15 minutes, and then washed twice. The coverslips were permeabilized with $0.25 \% \mathrm{v} / \mathrm{v}$ Triton-100 (Sigma-Aldrich) for $15 \mathrm{~min}$. After washing, coverslips were blocked with $2 \% \mathrm{w} / \mathrm{v}$ BSA for $1 \mathrm{~h}$ and incubated with ACE2 antibody [SN0754 (1:250) (GeneTex, GTX01160)], followed by Goat anti-rabbit IgG $(\mathrm{H}+\mathrm{L})$ cross-adsorbed secondary antibody (1:500) (Thermo Fisher Scientific) for $1 \mathrm{~h}$ at room temperature in dark. After incubation with secondary antibody, the cells were washed twice with PBS and mounted in the medium with DAPI (Abcam) on the slides to visualize under an upright fluorescence microscope (BX51; Olympus).

\section{Production of SARS-CoV-2 Pseudotyped Lentivirus}

The pseudotyped lentivirus carrying SARS-CoV-2 spike protein was generated by transiently transfecting HEK293T cells with pCMV-DR8.91, pLAS2w.Fluc.Ppuro and pcDNA3.1-nCoVSD18 (SARS-CoV-2 spike gene with 54 nucleotides deletion at its C-terminus was synthesized and cloned into pcDNA3.1 expression vector). HEK293T cells were seeded one day before, and then transfected with the indicated plasmids using TransIT ${ }^{\circledR}-\mathrm{LT} 1$ transfection reagent (Mirus). The culture medium was replenished at $16 \mathrm{~h}$ and harvested at $48 \mathrm{~h}$ and $72 \mathrm{~h}$ post-transfection. Cell debris was removed by centrifugation at 4,000 $\mathrm{x} \mathrm{g}$ for $10 \mathrm{~min}$, and the supernatant was passed through $0.45-\mathrm{mm}$ syringe filter (Pall Corporation). The pseudotyped lentivirus was aliquoted and stored at $-80^{\circ} \mathrm{C}$ until further use. The transduction unit (TU) of SARS-CoV-2 pseudotyped lentivirus was estimated using cell viability assay in response to the limited dilution of lentivirus. In brief, HEK293T cells, stably expressing human ACE2, were plated on 96-well plate one day before lentivirus transduction. For titrating, different amounts of lentivirus particles were added to the culture medium containing polybrene (final concentration $8 \mathrm{mg} / \mathrm{ml}$ ). Spin infection was carried out at $1,100 \mathrm{x} \mathrm{g}$ in 96 -well plate for $30 \mathrm{~min}$ at $37^{\circ} \mathrm{C}$. After Incubating cells at $37^{\circ} \mathrm{C}$ for $16 \mathrm{~h}$, the culture medium containing virus particles and polybrene was removed and replaced with fresh complete DMEM containing $2.5 \mu \mathrm{g} / \mathrm{ml}$ puromycin. After treating with puromycin for $48 \mathrm{~h}$, the culture media was removed, and the cell viability was assessed using $10 \%$ AlarmaBlue reagents, according to manufacturer's instruction. The survival of uninfected cells (without puromycin treatment) was set as $100 \%$. The virus particle titer (TU) was determined by plotting the survival of cells versus diluted viral dose.

\section{Pseudotyped Virus Neutralization Assay}

HEK293T cells in $10 \mathrm{~cm}$ petridishes were transfected with pCMV $\Delta$ R8.91, pcDNA nCoV-SD18 and pLAS2w.FLuc.Ppuro plasmids $(5,2,8 \mu \mathrm{g}$, respectively). Next day, cells were washed with PBS gently, and replaced with $10 \mathrm{ml}$ of fresh medium (RPMI containing 10\% FBS). The medium at 48 and $72 \mathrm{~h}$ were collected and stored in $-80^{\circ} \mathrm{C}$ for future use. HEK293T-ACE2 cells (HEK293T cells overexpressing ACE2 receptor) ( $0.5 \times 10^{5}$ cells) were pre-incubated with rfhSP-D $(0,5,10$ and $20 \mu \mathrm{g} / \mathrm{ml})$ for $24 \mathrm{~h}$ and then washed twice with PBS. The SARS-CoV-2 pseudotyped lentiviral particle containing medium $(500 \mu \mathrm{l} /$ well $)$ was added on to the cells, followed by incubation at $37^{\circ} \mathrm{C}$ under standard culture conditions. After $2 \mathrm{~h}$, fresh complete DMEM medium $(500 \mu \mathrm{l})$ was added on to the cells and incubated at $37^{\circ} \mathrm{C}$. Following $72 \mathrm{~h}$ incubation, the cells were washed with PBS twice, and incubated with lysis buffer at $37^{\circ} \mathrm{C}$ for $10 \mathrm{~min}$. Firefly luciferase activity (RLU) was measured using ONEGlo ${ }^{\text {TM }}$ Luciferase Assay System (Promega) and FlexStation.

\section{Statistical Analysis}

GraphPad Prism 6.0 software was used to generate all the graphs. Unpaired $t$ test was used for the statistical analysis. The significance values were considered between rfhSP-D treated and untreated conditions, based on ${ }^{\star} \mathrm{p}<0.05$. Error bars show the SEM (figure legends).

\section{RESULTS}

\section{Interaction of rfhSP-D and Recombinant Human Full-Length SP-D (hFL-SP-D) With S1 Protein and Its RBD}

In SARS-CoV, S-protein is the predominant surface glycoprotein recognized by the host innate immune system. The $S$ protein of SARS-CoV-2 has almost $76 \%$ identity to SARS-CoV. Previous studies indicated that SP-D bound S protein of SARS-CoV which required $\mathrm{Ca}^{2+}$; the binding was inhibited by maltose. Therefore, the first part of this study was aimed at examining the interaction of LPS-free rfhSP-D and hFL-SP-D with spike protein (S1) using direct binding ELISA. It was found that rfhSP-D/hFL-SP-D bound SARS-CoV-2 S1 protein in a dose-dependent manner (Figure 1A); this interaction was inhibited by maltose and EDTA (Figure 2A). Among varied concentrations of rfhSP-D tested, a strong and maximum binding of rfhSP-D with SARS-CoV-2 S1 $(5 \mu \mathrm{g} / \mathrm{ml})$ was observed at $10 \mu \mathrm{g} / \mathrm{ml}$.

The binding of SARS-CoV-2 to its cellular receptor, ACE2, is mediated by the RBD region of the $S$ protein. A higher binding 
A

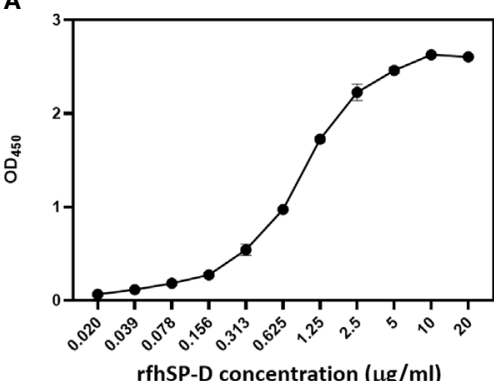

B

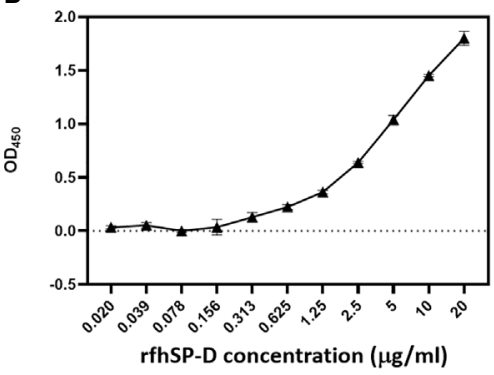

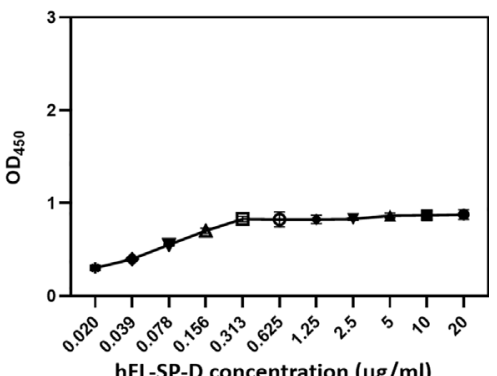

hFL-SP-D concentration $(\mu \mathrm{g} / \mathrm{ml})$

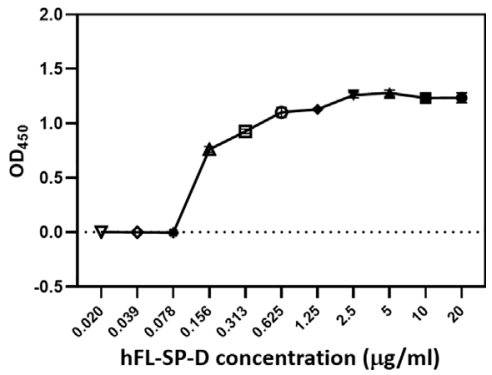

FIGURE 1 | rfhSP-D and recombinant human full-length SP-D (hFL-SP-D) binding with the spike (S1) (A) and its RBD (B) of the SARS-CoV-2 was determined via

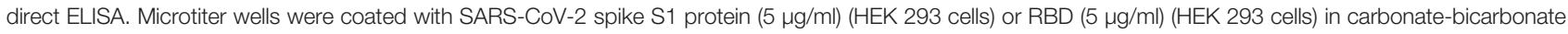
buffer, $\mathrm{pH} 9.6$ overnight at $4^{\circ} \mathrm{C}$. The following day, the wells were blocked with Tris Buffered Saline (TBS) buffer containing 1\% BSA and 5mM CaCl $2, \mathrm{pH} 7.2-7.4$. After washing the wells with TBS, the wells were incubated with a series of two-fold dilutions of rfhSP-D or hFL-SP-D protein in blocking buffer at $4^{\circ} \mathrm{C}$ overnight. The binding between S1 protein and rfhSP-D was detected using biotinylated mouse anti-Human SP-D detection antibody (1:180), followed by probing with Streptavidin horseradish peroxidase (HRP)-conjugate 1:40. The data were expressed as mean of three independent experiments done in triplicates \pm SEM. Significance was determined using the unpaired t test statistical analysis. The error bars show SEM. Control, maltose and EDTA groups compared to $2.5 \mu \mathrm{g}$ or $5 \mu \mathrm{g}$ S1 (RBD) in CaCl 2 .

affinity has been reported for RBD of SARS-COV-2 to ACE2 receptor compared to SARS-CoV (28). Furthermore, RBD of SARS-CoV-2 has been suggested to have a crucial role in spike protein-induced viral attachment, fusion, and entry into the host cells (29). In this context, this study was also aimed at determining the ability of rfhSP-D/hFL-SP-D to bind RBD of SARS-CoV-2 (Figure 1B) via direct ELISA (RBD coated, incubated with two-fold dilutions of rfhSP-D $(100 \mu \mathrm{g} / \mathrm{ml})$, and probed with anti-SP-D antibody; R\&D Systems). rfhSP-D bound RBD in a dosedependent manner. It reduced the binding affinity by maltose, but chelation of $\mathrm{Ca}^{2+}$ by EDTA did not significantly affect the interaction between rfhSP-D and RBD region (Figure 2B). No rfhSP-D binding was observed in the absence of RBD, indicating a lack of non-specific interaction in this assay. To further evaluate the dose response of Maltose and EDTA (5, 10 and 20mM), rfhSP-D was coated and probed with $\mathrm{S} 1$ and RBD (at 2.5 and $5 \mu \mathrm{g} / \mathrm{ml}$ ) (Figure 2B). These results suggest that the protein-protein interaction may occur between the CRD region of rfhSP-D and the $\mathrm{RBD}$ region of $\mathrm{S}$ protein in a calcium-independent manner.

\section{rfhSP-D Inhibits Interaction of SARS-CoV- 2 S1 With Membrane Expressed ACE2 on HEK293T Cells}

The 11 spike protein of the SARS-CoV-2 contains RBD that can recognise and interact with its cellular receptor, angiotensinconverting enzyme 2 (ACE2) $(30,31)$, thus mediating viral entry into the host cells. Since rfhSP-D was found to interact with the spike protein and its RBD at the protein level, we also tested the ability of rfhSP-D to interact with HEK293T cells overexpressing ACE2 receptor. Successful transfection of the ACE2 receptor gene into HEK293T cells was verified by measuring the expression levels of ACE2 receptor via immunofluorescence microscopy (Figure 3A), flow cytometry (Figure 3B) and western blotting (Figure 3C). Quantitative and qualitative analysis of the ACE2 receptor using ACE2 antibody (SN0754) revealed a higher signal for ACE2 on HEK293T-ACE2 cells when compared to HEK293T cells alone (Figures 3A, B). This study also focused on examining whether rfhSP-D treatment can inhibit the interaction between SARS-CoV-2 S1 and ACE2 receptor on HEK293T cells (Figure 4). Pre-incubation of SARS-CoV-2 S1 protein $(2 \mu \mathrm{g} / \mathrm{ml})$ with a varied concentration of rfhSP-D $(0.625-10 \mu \mathrm{g} / \mathrm{ml})$ was found to reduce S1 binding to HEK293T cells overexpressing ACE2 receptor in a dosedependent manner (Figure 4). The rfhSP-D at $10 \mu \mathrm{g} / \mathrm{ml}$ was found to reduce the binding of $\mathrm{S} 1$ to ACE2 receptor on HEK293T cells by approximately $7.95 \%$ when compared to the control (S1 + $0 \mu \mathrm{g} / \mathrm{ml} \mathrm{rfhSP-D)}$ (Figure 4).

\section{rfhSP-D Acts as an Entry Inhibitor of SARS-CoV-2 Infection}

After confirming the ability of rfhSP-D to prevent the interaction between SARS-CoV-2 S1 protein and HEK293T cells 


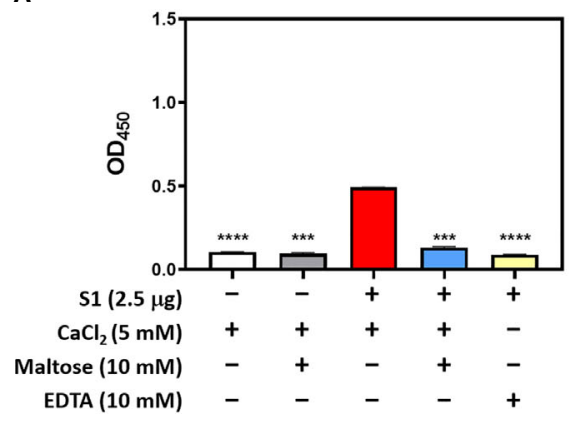

B

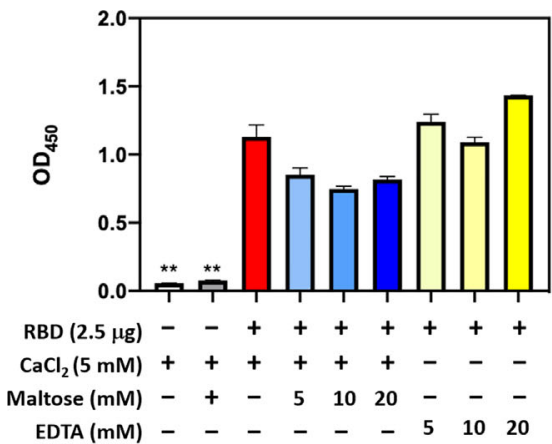

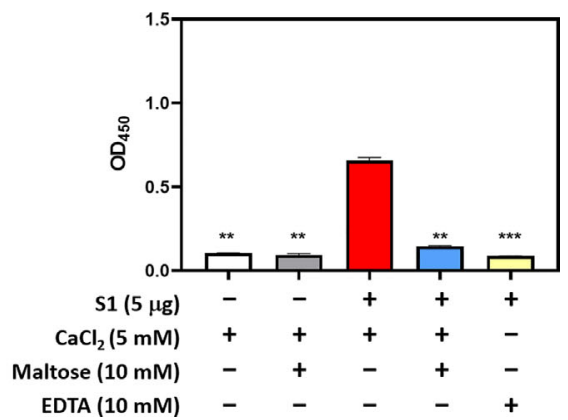

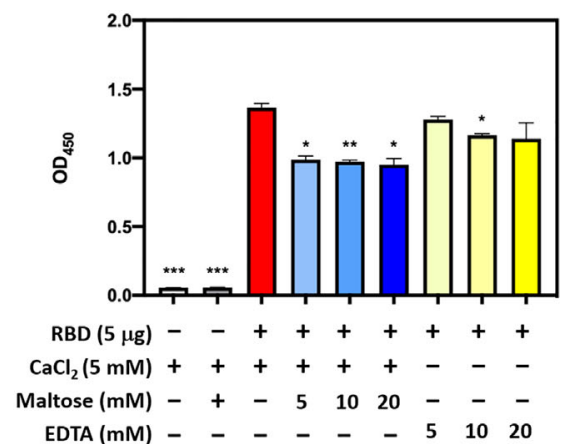

FIGURE 2 | Competitive ELISA to show the impact of Maltose and EDTA on rfhSP-D binding to S1 (A) and its RBD (B). Polystyrene microtiter plates were coated with $2 \mu \mathrm{g} / \mathrm{ml} \mathrm{rfhSP}-\mathrm{D}$, and incubated with SARS-CoV-2 spike S1 protein (2.5 and $5 \mu \mathrm{g} / \mathrm{ml})$ (sheep-lgG tag) or RBD (His-tag) $(2.5$ and $5 \mu \mathrm{g} / \mathrm{ml})$. The binding was detected using anti-sheep IgG HRP antibodies (1:2000) or anti-His antibodies (1:2000). Absorbance at 450nm were recorded by VersaMax ${ }^{\mathrm{TM}}$ ELISA Microplate Reader. Significance was determined using the unpaired $t$ test statistical analysis. The error bars show SEM. All group compared to $\mathrm{RBD}$ in $\mathrm{CaCl}_{2}\left({ }^{*} \mathrm{p}<0.05 ;{ }^{* *} \mathrm{p}<\right.$ $\left.0.01 ;{ }^{* \star *} \mathrm{p}<0.001 ;{ }^{* \star \star *} \mathrm{p}<0.0001\right)$.

overexpressing ACE2 receptor, we investigated whether rfhSP-D modulated viral entry using a luciferase reporter assay with pseudotyped lentiviral particles expressing SARS-CoV-2 S1 protein (Figure 5). SARS-CoV-2 pseudotyped lentiviral particles were produced as a safe strategy to study the involvement of S1 glycoprotein in the recognition and neutralization of the virus by a varied concentration of rfhSP-D. The production of lentiviral particles pseudotyped with envelope protein S1 was carried out by co-transfecting HEK293T cells with plasmid containing the coding sequence of the indicated pcDNA3.1-nCoV-SD18 (SARS-CoV-2 spike gene), pLAS2w.Fluc.Ppuro, and pCMV-DR8.91. Purified pseudotyped particles and cell lysate harvested at 48 and $72 \mathrm{~h}$ were analyzed via western blotting, and the expression level of SARS-CoV-2 spike protein was determined using anti-SARS-CoV-2 (COVID-19) Spike polyclonal antibody (Figure 5A). Cells pre-incubated rfhSP-D (5 and $10 \mu \mathrm{g} / \mathrm{ml}$ ) showed a significant $\sim 0.5$ RLU fold reduction in luciferase activity $\left(1.0 \times 10^{5} \mathrm{RLU}\right)$ compared to the cells+SARS-CoV-2 $\left(1.5 \times 10^{5} \mathrm{RLU}\right)$ (Figure $\left.5 \mathrm{~B}\right)$. The reduced luciferase activity, following treatment with rfhSP-D, indicated that the interaction between rfhSP-D and SARS-CoV-2 S1 protein interfered with $\mathrm{S} 1$-containing viral particle binding to ACE2, and hence, prevented the entry of the virus into the HEK323T-ACE2 cells (Figure 5).

\section{DISCUSSION}

The innate immune system has evolved cellular and molecular defense mechanisms critical for the recognition and restriction of SARS-CoV-2-mediated respiratory tract infections, and for the activation of subsequent adaptive immune responses (32). SARSCoV-2 infection is responsible for a higher transmissibility, mortality and morbidity rates that has caused the current global pandemic (33-35). Given that the SARS-CoV-2 is a newly emerged pandemic infection, it is fundamentally crucial to understand the role of host innate and adaptive immune response, which in turn, is likely to have profound impact on designing and developing effective anti-SARS-CoV-2 therapies.

The primary target for SARS-CoV-2 is the alveolar epithelial type II cells (36), and the viral entry to the host cell is mediated by the ACE2 receptor (37). Furthermore, viral entry into the host cells also depends on the activity of TMPRSS2 protease as it facilitates $S$ protein cleavage into $S 1$ and S2 portions. This enables S-mediated targeting and receptor-mediated early fusion pathway driven by the S2 subunit (19). The present study confirmed the ability of rfhSP-D to act as an entry inhibitor of pseudotyped lentiviral particles expressing SARSCoV-2 S1 protein in hACE-2 overexpressing HEK293T cells mimicking the human SARS-CoV-2 infection. 


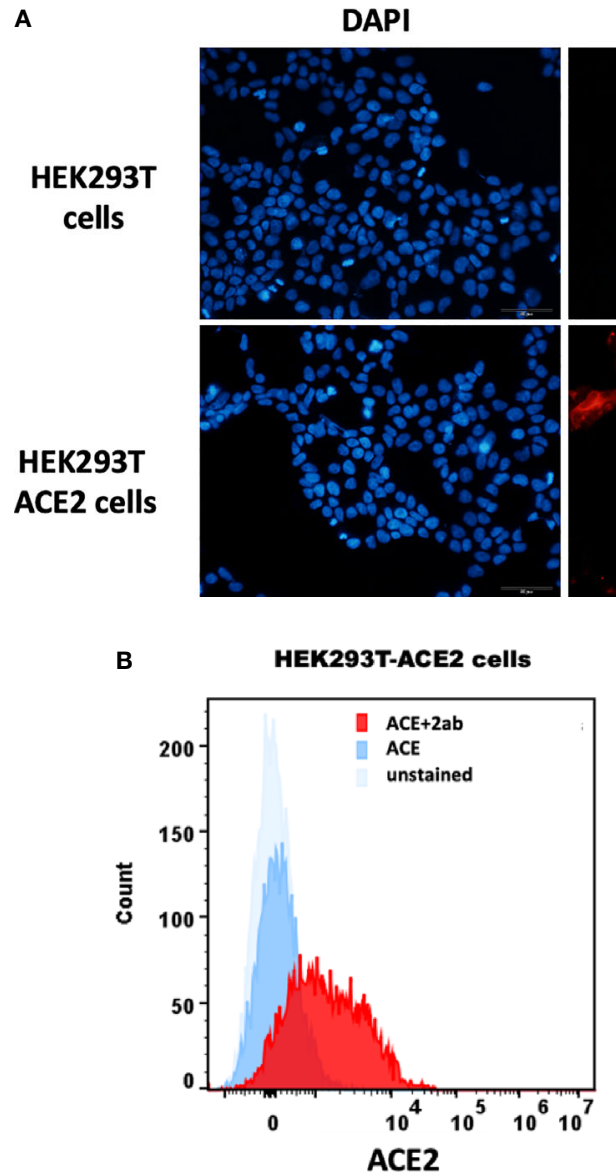

C

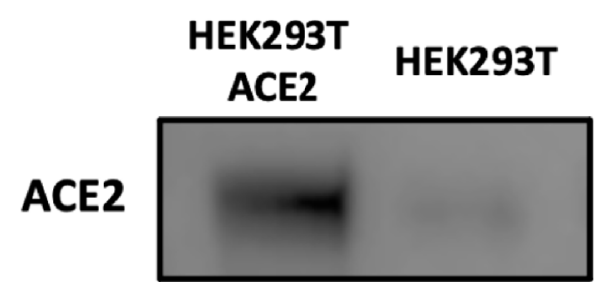

ACE 2

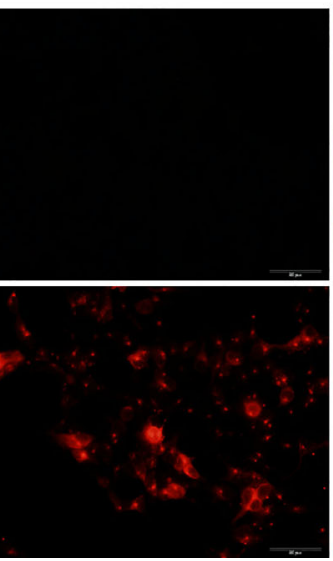

HEK293T cells

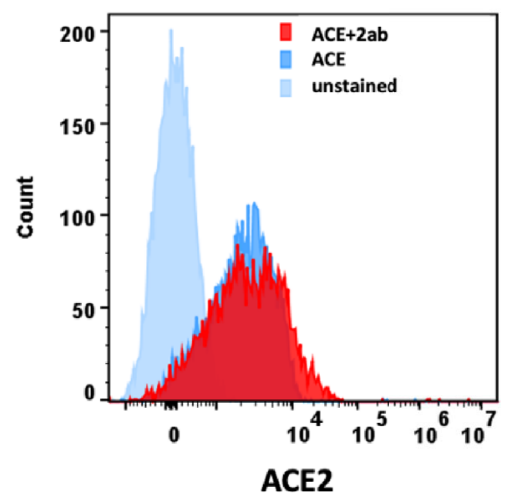

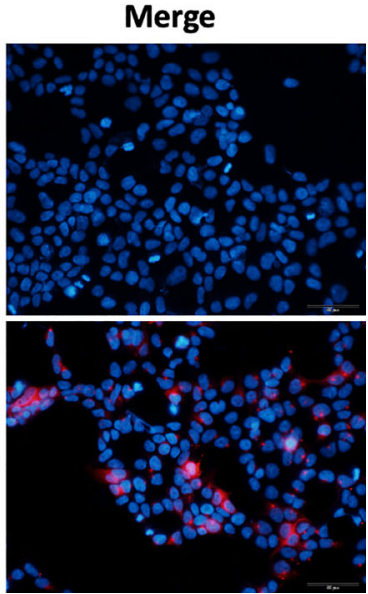

FIGURE 3 | Expression of ACE2 receptor on HEK293T cells by immunofluorescence microscopy (A), flow cytometry (B) and western blotting (C). (A) HEK293T $\left(0.5 \times 10^{5}\right.$ cells $)$ and HEK293T-ACE2 cells $\left(0.5 \times 10^{5}\right.$ cells) were seeded on coverslips, followed by incubation at $37^{\circ} \mathrm{C}$ under standard culture conditions. After wasing the cells with PBS twice, the ACE2 expression was detected in both cell lines using the ACE2 antibody [SN0754](1:250), followed byincubation for $1 \mathrm{~h}$ at room temperature. Following PBS washes, Goat anti-rabbit IgG $(\mathrm{H}+\mathrm{L})$ cross-adsorbed secondary antibody (1:500) was added. Following PBS washes, the coverslips were mounted in medium with DAPI on a microscopy slide and viewed under a fluorescence microscope (Olympus). (B) Flow cytometric analysis of ACE2 expression was determined by the shift in the fluorescence intensity using ACE2 antibody [N1N2], N-term (GeneTex) (1:250). The ACE2 expression was detected by CytoFLEX.

(C) The ACE2 expression was examined by western blotting using ACE2 antibody [SN0754] (GeneTex) (1:1000).

Human SP-D is a lung collectin, synthesized by Clara cells (38) and alveolar type-II cells (1). Anti-viral role of SP-D has been reported against HIV-1 and IAV infection $(5,6,8,39,40)$. In addition, increased serum SP-D has been observed in SARSCoV and SARS-CoV-2 patients $(11,41)$. Interaction between SP$\mathrm{D}$ and the $\mathrm{S}$ protein of SARS-CoV leads to enhanced phagocytosis $(11,12)$. Furthermore, SP-D can also inhibit viral infection of 16HBE cells infected with HCoV-229E (13). However, SP-D-mediated inhibition of SARS-CoV infection and its subsequent immune response is not fully studied. Therefore, this study was aimed at examining the ability of rfhSP-D to act as an entry inhibitor of SARS-CoV-2 infection using pseudotyped lentiviral particles expressing SARS-CoV-2 $\mathrm{S} 1$ protein. Being a potent innate immune molecule present in 

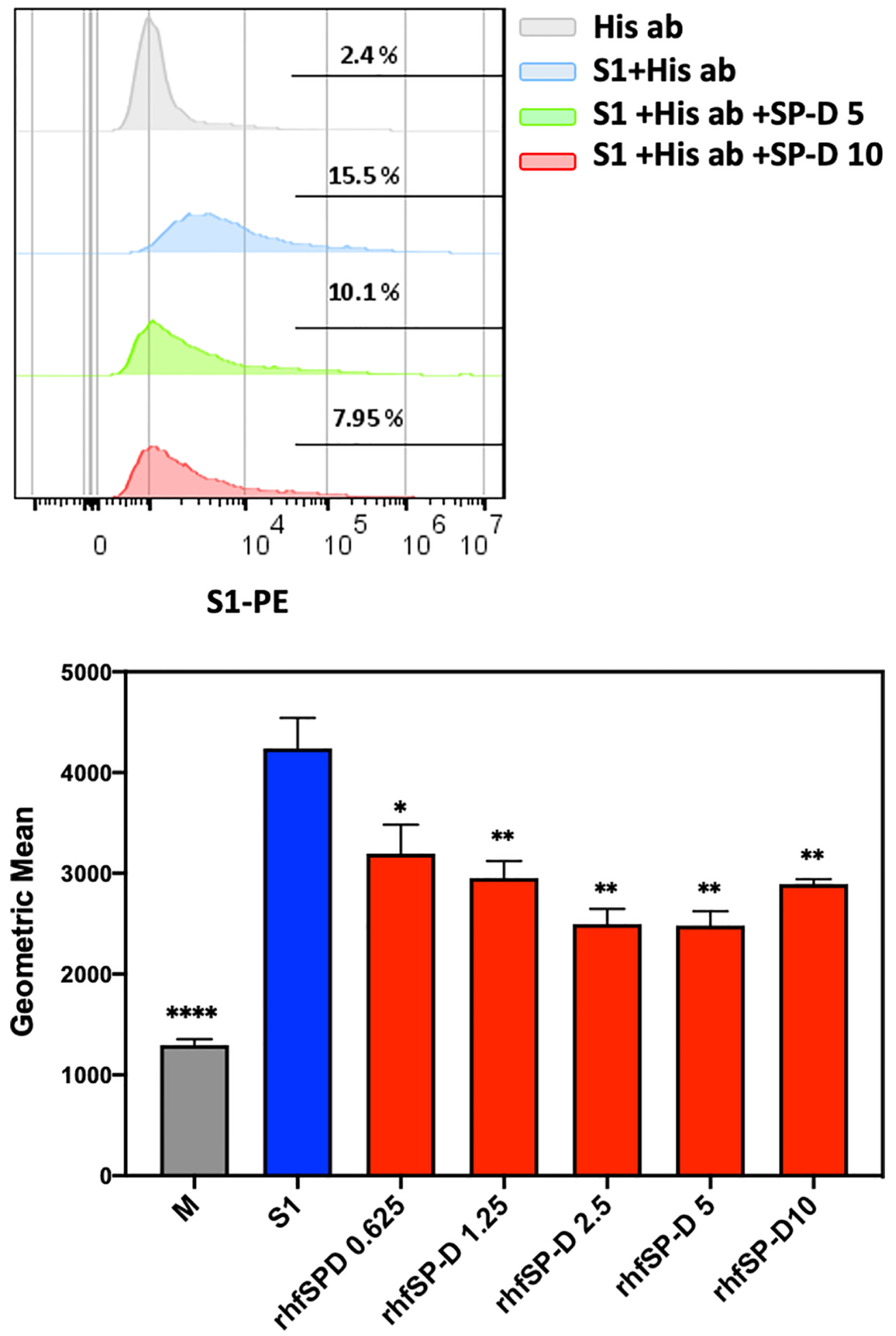

FIGURE 4 | rfhSP-D treatment inhibits the interaction between SARS-CoV-2 S1 and ACE2 receptor on HEK293T cells. Protein complex was made by tagging SARS-CoV-2 S1 protein ( $5 \mathrm{ug} / \mathrm{ml})$ with anti-His antibody (10ug/ml), followed by incubation with rfhSP-D (0.625, 1.25, 2.5, 5 or $10 \mu \mathrm{g} / \mathrm{ml})$ for $2 \mathrm{~h}$ at room temperature. This complex (S1+ anti-His+rfhSP-D) was added on to HEK293T-ACE2 cells ( $1 \times 10^{5}$ cells) at $37^{\circ} \mathrm{C}$ for $2 \mathrm{~h}$. The cells were collected and washed with FACS buffer twice and incubated with anti-mouse IgG PE conjugate (Genetex, GTX25881) (1:100) for 30 min and washed three times. The cells stained with S1 were detected by CytoFLEX. Significance was determined using the unpaired t test statistical analysis. All groups compared to $\mathrm{S} 1$. The error bars show SEM. M=mock ( ${ }^{*} \mathrm{p}<0.05$; $\left.{ }^{\star *} \mathrm{p}<0.01 ;{ }^{* \star \star *} \mathrm{p}<0.0001\right)(\mathrm{n}=3)$ 
A

\section{VSV VSV M BSA}

S1

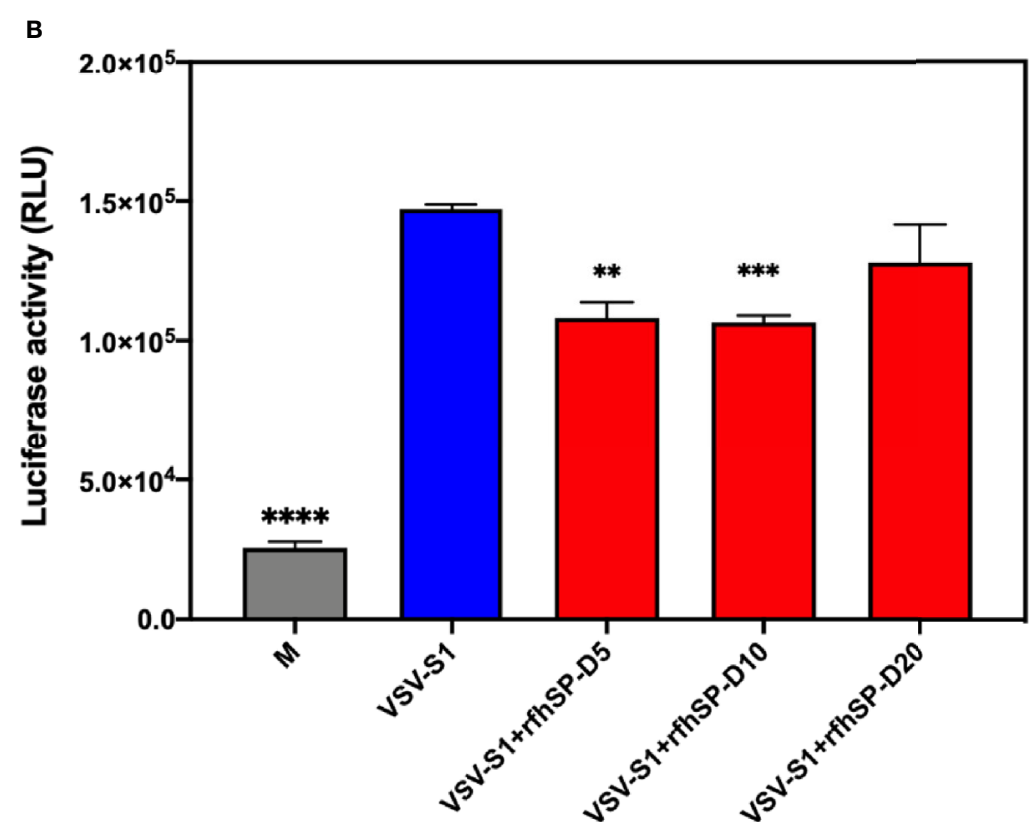

FIGURE 5 | rfhSP-D acts as an entry inhibitor of SARS-CoV-2 infection. (A) The SARS-CoV-2 pseudotyped lentiviral particle and pseudotyped lentiviral particle containing medium were determined the S1 expression by western blotting. (B) Luciferase reporter activity of rfhSP-D treated HEK293T cells (overexpressing ACE2 receptor) transduced with of SARS-CoV-2 S1 pseudotyped lentiviral particles. Significance was determined using the unpaired t test statistical analysis. All groups compared to VSV-S1. The error bars show SEM. M=medium $\left({ }^{\star *} p<0.01 ;{ }^{* \star *} p<0.001 ;{ }^{* \star *} p<0.0001\right)(n=3)$.

the lung surfactant, SP-D is expected to play an important protective role in the pathogenesis of COVID-19.

Owing to a significant similarity in the $\mathrm{S}$ proteins of SARS-CoV and SARS-CoV-2, it was hypothesized that SP-D may interact with $S$ protein of SARS-CoV-2. The results confirmed that affinity purified, and LPS-free rfhSP-D interacted with S1 protein of SARS-CoV-2 and its RBD in a dose-dependent manner akin to the recombinant hFLSP-D. Inhibition of rfhSP-D binding to $S$ protein by EDTA or maltose suggested that rfhSP-D bound to the carbohydrate moieties on S protein of SARS-CoV-2 (12). We also examined whether rfhSP-D treatment can inhibit the interaction of SARS-CoV-2 S1 with ACE2 receptor on HEK293T cells. SARSCoV-2 S1 protein $(5 \mu \mathrm{g} / \mathrm{ml})$, pre-incubated with a varied concentration of rfhSP-D $(0.625-10 \mu \mathrm{g} / \mathrm{ml})$, showed reduced binding to HEK293T cells overexpressing ACE2 receptor in a dose-dependent manner.

Targeting viral entry into a host cell is an emerging approach for designing and developing anti-viral therapies as viral propagation can be either restricted or blocked at an early stage of viral cycle, diminishing drug resistance by released viral particles. In this study, we examined the entry inhibitor role of rfhSP-D against SARS-CoV-2 by luciferase reporter assay. Pseudotyped lentiviral particles were generated as a safe alternative method to mimic the structural surface of SARSCoV-2, and to test whether rfhSP-D treatment can promote or prevent viral entry into the host cells. Approximately $0.5 \mathrm{RLU}$ fold reduction was seen with rfhSP-D (5 or $10 \mu \mathrm{g} / \mathrm{ml}$ ) treatment when compared to untreated sample (1 RLU fold; Cells + SARSCoV-2). A significantly reduced luminescent signal following rfhSP-D treatment indicated that the interaction of rfhSP-D with SARS-CoV-2-S1 restricted the binding and entry of the virus, suggestive of an entry inhibitory role of rfhSP-D against SARS$\mathrm{CoV}-2$ infection.

SARS-CoV-2 mediated lung injury is correlated with diffuse alveolar damage and air space oedema, thus, accompanied by interstitial infiltration of inflammatory cells, triggering of coagulation, and fibrin deposition (42-45). Potential biomarkers to be considered during SARS infection include increased levels of inflammatory plasma makers, coagulation, and fibrinolysis $(46,47)$. Damage to the alveolar epithelial barrier 
is a characteristic feature of an acute respiratory distress syndrome (ARDS) and acute lung injury (ALI); levels of plasma surfactant proteins such as SP-A and SP-D may have a prognostic value (4850). Thus, this study prompts further investigation into the role of pulmonary surfactant in COVID-19.

In summary, rfhSP-D, containing homotrimeric neck and CRD regions, acts as an entry inhibitor of SARS-CoV-2 infection by restricting the viral entry into HEK293T cells overexpressing ACE2 receptor. Time is ripe for taking the knowledge about the involvement of rfhSP-D and its associated anti-viral effects forward to develop a novel therapeutic approach to target multiple cellular signaling pathways. The mechanisms which enable rfhSP-D to trigger anti-viral effect are virus-specific due to the differential effect and variation in terms of the cell types and putative receptors. There is a clear therapeutic potential of rfhSP-D against SARS-CoV-2; although increased glycosylation of spike protein leads to evasion of antibody susceptibility, it is expected to enhance the susceptibility of the virus to soluble pattern recognition receptors (PRRs) such as SP-D. Having established the specific nature of interactions between rfhSP-D and SARS-CoV-2, we hope to examine host response in the murine models of infection using wild type and SP-D knock-out mice.

\section{REFERENCES}

1. Kishore U, Greenhough TJ, Waters P, Shrive AK, Ghai R, Kamran MF, et al. And SP-D: Structure, Function and Receptors. Mol Immunol (2006) 43 (9):1293-315. doi: 10.1016/j.molimm.2005.08.004

2. Crouch E, Parghi D, Kuan S, Persson A. Surfactant Protein D: Subcellular Localization in Nonciliated Bronchiolar Epithelial Cells. Am J Physiol-Lung Cell Mol Physiol (1992) 263(1):L60-6. doi: 10.1152/ajplung.1992.263.1.L60

3. Voorhout W, Veenendaal T, Kuroki Y, Ogasawara Y, Van Golde L, Geuze H. Immunocytochemical Localization of Surfactant Protein D (Sp-D) in Type II Cells, Clara Cells, and Alveolar Macrophages of Rat Lung. J Histochem Cytochem (1992) 40(10):1589-97. doi: 10.1177/40.10.1527377

4. Nayak A, Dodagatta-Marri E, Tsolaki AG, Kishore U. An Insight Into the Diverse Roles of Surfactant Proteins, SP-A and SP-D in Innate and Adaptive Immunity. Front Immunol (2012) 3:131. doi: 10.3389/fimmu.2012.00131

5. Hartshorn KL, Crouch EC, White MR, Eggleton P, Tauber AI, Chang D, et al. Evidence for a Protective Role of Pulmonary Surfactant Protein D (Sp-D) Against Influenza A Viruses. J Clin Invest (1994) 94(1):311-9. doi: 10.1172/ JCI117323

6. Hartshorn KL, White MR, Voelker DR, Coburn J, Zaner K, Crouch EC. Mechanism of Binding of Surfactant Protein D to Influenza A Viruses: Importance of Binding to Haemagglutinin to Antiviral Activity. Biochem J (2000) 351(Pt 2):449-58. doi: 10.1042/bj3510449

7. Hillaire ML, Haagsman HP, Osterhaus AD, Rimmelzwaan GF, van Eijk M. Pulmonary Surfactant Protein D in First-Line Innate Defence Against Influenza A Virus Infections. J Innate Immun (2013) 5(3):197-208. doi: $10.1159 / 000346374$

8. Al-Ahdal MN, Murugaiah V, Varghese PM, Abozaid SM, Saba I, Al-Qahtani $\mathrm{AA}$, et al. Entry Inhibition and Modulation of Pro-Inflammatory Immune Response Against Influenza A Virus by a Recombinant Truncated Surfactant Protein D. Front Immunol (2018) 9:1586. doi: 10.3389/fimmu.2018.01586

9. Meschi J, Crouch EC, Skolnik P, Yahya K, Holmskov U, Leth-Larsen R, et al. Surfactant Protein D Binds to Human Immunodeficiency Virus (HIV) Envelope Protein gp120 and Inhibits HIV Replication. J Gen Virol (2005) 86(11):3097-107. doi: 10.1099/vir.0.80764-0

10. Pandit H, Gopal S, Sonawani A, Yadav AK, Qaseem AS, Warke H, et al. Surfactant Protein D Inhibits HIV-1 Infection of Target Cells Via Interference With Gp120-CD4 Interaction and Modulates Pro-Inflammatory Cytokine

\section{DATA AVAILABILITY STATEMENT}

The raw data supporting the conclusions of this article will be made available by the authors, without undue reservation.

\section{AUTHOR CONTRIBUTIONS}

$\mathrm{M}-\mathrm{HH}$ and NB carried out crucial experiments that were validated by Y-CC, W-SK and H-FK. M-HH, VM, UK, and J-YW analysed the data. VM, TM, UK, and J-YW prepared the manuscript. All authors contributed to the article and approved the submitted version.

\section{FUNDING}

J-YW is supported by the Ministry of Science and Technology (MOST) in Taiwan under grant nos. MOST 107-2314-B-006 $-046-$ MY1-3, and received funding in part from the Headquarters of University Advancement at the National Cheng Kung University, which is sponsored by the Ministry of Education in Taiwan.

Production. PLoS One (2014) 9(7):e102395. doi: 10.1371/journal. pone. 0102395

11. Wu YP, Liu ZH, Wei R, Pan SD, Mao NY, Chen B, et al. Elevated Plasma Surfactant Protein D (Sp-D) Levels and a Direct Correlation With Anti-Severe Acute Respiratory Syndrome Coronavirus-Specific IgG Antibody in SARS Patients. Scand J Immunol (2009) 69(6):508-15. doi: 10.1111/j.13653083.2009.02245.x

12. Leth-Larsen R, Zhong F, Chow VT, Holmskov U, Lu J. The SARS Coronavirus Spike Glycoprotein is Selectively Recognized by Lung Surfactant Protein D and Activates Macrophages. Immunobiology (2007) 212(3):201-11. doi: 10.1016/j.imbio.2006.12.001

13. Funk CJ, Wang J, Ito Y, Travanty EA, Voelker DR, Holmes KV, et al. Infection of Human Alveolar Macrophages by Human Coronavirus Strain 229E. J Gen Virol (2012) 93(Pt 3):494-503. doi: 10.1099/vir.0.038414-0

14. Yan R, Zhang Y, Li Y, Xia L, Guo Y, Zhou Q. Structural Basis for the Recognition of SARS-CoV-2 by Full-Length Human ACE2. Science (2020) 367(6485):1444-8. doi: 10.1126/science.abb2762

15. Ludwig $S$ and Zarbock A. Coronaviruses and SARS-Cov-2: A Brief Overview. Anesth Analg (2020) 131(1):93-6. doi: 10.1213/ANE.0000000000004845

16. Kim JM, Chung YS, Jo HJ, Lee NJ, Kim MS, Woo SH, et al. Identification of Coronavirus Isolated From a Patient in Korea With COVID-19. Osong Public Health Res Perspect (2020) 11(1):3-7. doi: 10.24171/j.phrp.2020.11.1.02

17. Varghese PM, Tsolaki AG, Yasmin H, Shastri A, Ferluga J, Vatish M, et al. Host-Pathogen Interaction in COVID-19: Pathogenesis, Potential Therapeutics and Vaccination Strategies. Immunobiology (2020) 225 (6):152008. doi: 10.1016/j.imbio.2020.152008

18. Astuti I. And Ysrafil, Severe Acute Respiratory Syndrome Coronavirus 2 (SARS-Cov-2): An Overview of Viral Structure and Host Response. Diabetes Metab Syndr (2020) 14(4):407-12. doi: 10.1016/j.dsx.2020.04.020

19. Hoffmann M, Kleine-Weber H, Schroeder S, Kruger N, Herrler T, Erichsen S, et al. SARS-Cov-2 Cell Entry Depends on ACE2 and TMPRSS2 and Is Blocked by a Clinically Proven Protease Inhibitor. Cell (2020) 181(2):271-80.e8. doi: 10.1016/j.cell.2020.02.052

20. Matsuyama S, Nao N, Shirato K, Kawase M, Saito S, Takayama I, et al. Enhanced Isolation of SARS-CoV-2 by TMPRSS2-expressing Cells. Proc Natl Acad Sci (2020) 117(13):7001-3. doi: 10.1073/pnas.2002589117

21. Gubernatorova EO, Gorshkova EA, Polinova AI, Drutskaya MS. Il-6: Relevance for Immunopathology of SARS-Cov-2. Cytokine Growth Factor $\operatorname{Rev}(2020)$ 53:13-24. doi: 10.1016/j.cytogfr.2020.05.009 
22. Ratajczak MZ and Kucia M. Sars-CoV-2 Infection and Overactivation of Nlrp3 Inflammasome as a Trigger of Cytokine "Storm" and Risk Factor for Damage of Hematopoietic Stem Cells. Leukemia (2020) 34(7):1726-9. doi: 10.1038/s41375-020-0887-9

23. Torres Acosta MA, Singer BD. Pathogenesis of COVID-19-induced ARDS: Implications for an Ageing Population. Eur Respir J (2020) 56(3):1-12. doi: 10.1183/13993003.02049-2020

24. D’Abramo A, Lepore L, Palazzolo C, Barreca F, Liuzzi G, Lalle E, et al. Acute Respiratory Distress Syndrome Due to SARS-CoV-2 and Influenza A CoInfection in an Italian Patient: Mini-review of the Literature. Int J Infect Dis (2020) 97:236-9. doi: 10.1016/j.ijid.2020.06.056

25. Kaur A, Riaz MS, Murugaiah V, Varghese PM, Singh SK, Kishore U. A Recombinant Fragment of Human Surfactant Protein D Induces Apoptosis in Pancreatic Cancer Cell Lines Via Fas-Mediated Pathway. Front Immunol (2018) 9:1126. doi: 10.3389/fimmu.2018.01126

26. Murugaiah V, Agostinis C, Vargheses P, Belmonte B, Vieni S, Alaql F, et al. Hyaluronic Acid Present in the Tumour Microenvironment can Negate the Pro-Apoptotic Effect of a Recombinant Fragment of Human Surfactant Protein-D on Breast Cancer Cells. Front Immunol (2020) 11(1171):1-17. doi: 10.3389/fimmu.2020.01171

27. Wang C, Li W, Drabek D, Okba NMA, van Haperen R, Osterhaus A, et al. A Human Monoclonal Antibody Blocking SARS-CoV-2 Infection. Nat Commun (2020) 11(1):2251. doi: 10.1038/s41467-020-16256-y

28. Shang J, Ye G, Shi K, Wan Y, Luo C, Aihara H, et al. Structural Basis of Receptor Recognition by SARS-Cov-2. Nature (2020) 581(7807):221-4. doi: 10.1038/s41586-020-2179-y

29. Ortega JT, Serrano ML, Pujol FH, Rangel HR. Role of Changes in SARS-CoV2 Spike Protein in the Interaction With the Human ACE2 Receptor: An in Silico Analysis. EXCLI J (2020) 19:410-7. doi: 10.17179/excli2020-1167

30. Wan Y, Shang J, Graham R, Baric RS, Li F. Receptor Recognition by the Novel Coronavirus From Wuhan: An Analysis Based on Decade-Long Structural Studies of SARS Coronavirus. J Virol (2020) 94(7):1-9. doi: 10.1128/ JVI.00127-20

31. Li F. Receptor Recognition Mechanisms of Coronaviruses: A Decade of Structural Studies. J Virol (2015) 89(4):1954-64. doi: 10.1128/JVI.02615-14

32. Fung TS and Liu DX. Human Coronavirus: Host-Pathogen Interaction. Annu Rev Microbiol (2019) 73:529-57. doi: 10.1146/annurev-micro-020518-115759

33. Zhong N, Zheng B, Li Y, Poon L, Xie Z, Chan K, et al. Epidemiology and Cause of Severe Acute Respiratory Syndrome (SARS) in Guangdong, People's Republic of China, in February, 2003. Lancet (2003) 362(9393):1353-8. doi: 10.1016/S0140-6736(03)14630-2

34. Anderson RM, Fraser C, Ghani AC, Donnelly CA, Riley S, Ferguson NM, et al. Epidemiology, Transmission Dynamics and Control of SARS: The 2002-2003 Epidemic. Philos Trans R Soc London Ser B: Biol Sci (2004) 359(1447):1091105. doi: 10.1098/rstb.2004.1490

35. Heymann DL. The International Response to the Outbreak of SARS in 2003. Philosophical Transactions of the Royal Society of London. Ser B: Biol Sci (2004) 359(1447):1127-9. doi: 10.1098/rstb.2004.1484

36. Xu J, Xu X, Jiang L, Dua K, Hansbro PM, Liu G. Sars-CoV-2 Induces Transcriptional Signatures in Human Lung Epithelial Cells That Promote Lung Fibrosis. Respir Res (2020) 21(1):182. doi: 10.1186/s12931-020-01445-6

37. Perrotta F, Matera MG, Cazzola M, Bianco A. Severe Respiratory SARS-CoV2 Infection: Does ACE2 Receptor Matter? Respir Med (2020) 168:105996. doi: 10.1016/j.rmed.2020.105996
38. Crouch E, Hartshorn K, Horlacher T, McDonald B, Smith K, Cafarella T, et al. Recognition of Mannosylated Ligands and Influenza A Virus by Human Surfactant Protein D: Contributions of an Extended Site and Residue 343. Biochemistry (2009) 48(15):3335-45. doi: 10.1021/bi8022703

39. Ng WC, Tate MD, Brooks AG, Reading PC. Soluble Host Defense Lectins in Innate Immunity to Influenza Virus. J BioMed Biotechnol (2012) 2012:732191. doi: 10.1155/2012/732191

40. Hartshorn KL, Webby R, White MR, Tecle T, Pan C, Boucher S, et al. Role of Viral Hemagglutinin Glycosylation in Anti-Influenza Activities of Recombinant Surfactant Protein D. Respir Res (2008) 9:65. doi: 10.1186/1465-9921-9-65

41. Kerget B, Kerget F, Kocak AO, Kiziltunc A, Araz O, Ucar EY, et al. Are Serum Interleukin 6 and Surfactant Protein D Levels Associated With the Clinical Course of COVID-19? Lung (2020) 198(5):777-84. doi: 10.1007/s00408-02000393-8

42. Chen J and Subbarao K. The Immunobiology of SARS. Annu Rev Immunol (2007) 25:443-72. doi: 10.1146/annurev.immunol.25.022106.141706

43. Lee N, Hui D, Wu A, Chan P, Cameron P, Joynt GM, et al. A Major Outbreak of Severe Acute Respiratory Syndrome in Hong Kong. N Engl J Med (2003) 348(20):1986-94. doi: 10.1056/NEJMoa030685

44. Wu YP, Wei R, De Groot PG. SARS in Hong Kong. N Engl J Med (2003) 349 (7):708-9. doi: 10.1056/NEJMc031468

45. Ng K, Wu A, Cheng V, Tang B, Chan C, Yung C, et al. Pulmonary Artery Thrombosis in a Patient With Severe Acute Respiratory Syndrome. Postgrad Med J (2005) 81(956):e3-3. doi: 10.1136/pgmj.2004.030049

46. Chen B, Lisman T, Ren D. Analysis of Thrombotic Factors in Severe Acute Respiratory Syndrome (SARS) Patients. Thromb Haemost (2006) 96(07):1001. doi: 10.1160/TH05-12-0827

47. Liu Z-H, Wei R, Wu Y-P, Lisman T, Wang Z-X, Han J-J, et al. Elevated Plasma Tissue-Type Plasminogen Activator (t-PA) and Soluble Throm-Bomodulin in Patients Suffering From Severe Acute Respiratory Syndrome (SARS) as a Possible Index for Prognosis and Treatment Strategy. Biomed Environ Sci (2005) 18(4):260-4.

48. Matthay MA and Zemans RL. The Acute Respiratory Distress Syndrome: Pathogenesis and Treatment. Annu Rev Pathol: Mech Dis (2011) 6:147-63. doi: 10.1146/annurev-pathol-011110-130158

49. Greene KE, Wright JR, Steinberg KP, Ruzinski JT, Caldwell E, WB W, et al. Serial Changes in Surfactant-Associated Proteins in Lung and Serum Before and After Onset of ARDS. Am J Respir Crit Care Med (1999) 160(6):1843-50. doi: 10.1164/ajrccm.160.6.9901117

50. Endo S, Sato N, Nakae H, Yamada Y, Makabe H, Abe H, et al. Surfactant Protein A and D (Sp-a, AP-D) Levels in Patients With Septic ARDS. Res Commun Mol Pathol Pharmacol (2002) 111(5-6):245.

Conflict of Interest: The authors declare that the research was conducted in the absence of any commercial or financial relationships that could be construed as a potential conflict of interest.

Copyright (C) 2021 Hsieh, Beirag, Murugaiah, Chou, Kuo, Kao, Madan, Kishore and Wang. This is an open-access article distributed under the terms of the Creative Commons Attribution License (CC BY). The use, distribution or reproduction in other forums is permitted, provided the original author(s) and the copyright owner(s) are credited and that the original publication in this journal is cited, in accordance with accepted academic practice. No use, distribution or reproduction is permitted which does not comply with these terms. 